\title{
Ley Modelo de Sistemas Comunitarios de Agua y Saneamiento para América Latina y el Caribe
}

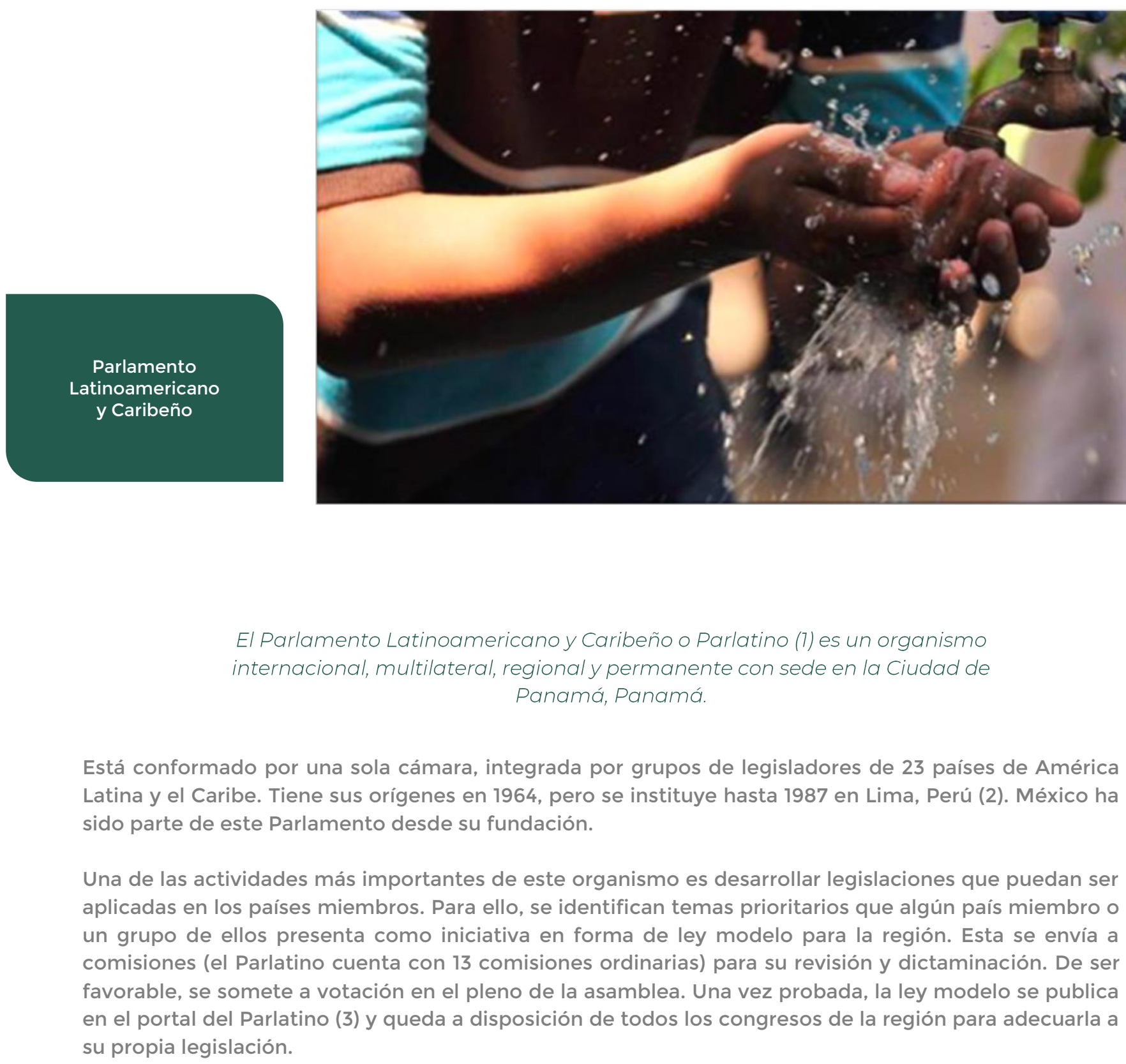


En noviembre de 2012, año en el que México modificó su constitución para incorporar los derechos humanos al agua y saneamiento (4), el Parlatino aprobó una ley modelo denominada Ley Marco sobre el Derecho Humano al Agua Potable y Saneamiento (5). En su artículo 8, dicha ley establece la obligación que tienen los Estados de respetar los "sistemas consuetudinarios o tradicionales" de distribución de agua potable. Así, en el marco del Parlatino, por primera vez se hace referencia a los sistemas comunitarios que ofrecen el servicio de agua potable en comunidades rurales (principalmente). Esta mención es el antecedente de una iniciativa que México promoverá a través de sus representantes en el Parlatino.

Conocidas como organizaciones comunitarias de servicios de agua y saneamiento (Ocsas) o sistemas comunitarios de agua y saneamiento (SCAS), estas organizaciones abastecen de agua a zonas rurales, periurbanas y, en algunos casos, urbanas. Para el año 2017 se estimaba que existían más de 80,000 Ocsas en la región (6). En países como México, dónde los organismos operadores de agua potable y saneamiento municipales no logran cubrir la totalidad del territorio de sus demarcaciones, en particular zonas rurales, los SCAS son responsables de suplir este servicio público.

Desafortunadamente, en toda la región, estos sistemas son poco reconocidos por los marcos legales nacionales. Esto impide que accedan a recursos fiscales y a oportunidades de fortalecimiento de capacidades por parte del Estado, lo que las mantiene al margen del desarrollo equitativo e integral. De esta manera, el potencial de los SCAS para proveer efectivamente agua potable y servicios de saneamiento para millones de personas en la región no es aprovechado por falta de reconocimiento institucional.

Esta falta de reconocimiento legal limita indirectamente los derechos humanos asociados con el agua, así como el cumplimiento efectivo del Objetivo de Desarrollo Sostenible (ODS) 6 (Agua Limpia y Saneamiento) (7) acordado por los países en el marco de la Agenda 2030.

Dado que es el Estado quien debe garantizar los derechos humanos asociados con el agua, pero también quien debe promover la participación de la sociedad en la toma de decisiones (ODS 16.7) (8), fortalecer los SCAS es una medida directa para promover, fomentar, respetar y garantizar estos derechos, cumpliendo así con metas específicas de la Agenda 2030.

Los SCAS tienen la cualidad de ser resultado de acuerdos comunitarios, por lo que promueven la asociatividad comunitaria (9) y la cogestión del agua. Sirven como la primera línea de defensa ante embates sanitarios y climáticos, e impulsan la resiliencia local al promover la organización comunitaria. Los SCAS tienen la virtud de potenciar espacios de gobernanza, además de desarrollar capacidades administrativas y de negociación entre múltiples actores. Podemos afirmar que los SCAS son escuelas de ciudadanía.

Por último, los SCAS tienen particular relevancia cuando hablamos de pueblos indígenas y comunidades equiparables, ya que reconocen su derecho consuetudinario, prácticas tradicionales de gobierno y formas comunitarias de control sobre sus territorios.

Las parlamentarias mexicanas, la diputada Dolores Padierna y la senadora Ana Lilia Rivera, integrantes del Frente Parlamentario contra el Hambre de México (10), la Agencia Mexicana de Cooperación Internacional para el Desarrollo y el Instituto Mexicano de Tecnología del Agua, en colaboración con la oficina de FAO-Mesoamérica, estamos preparando de manera conjunta una iniciativa de Ley Modelo de Sistemas Comunitarios de Agua y Saneamiento para América Latina y el Caribe, que dé certeza jurídica a estos sistemas, fortalezca sus capacidades organizacionales y operativas, y reconozca su papel 
PERSPECTIVAS IMTA (0)

$N^{\circ} .4,2020$

Autores: Alberto Roja Rueda, Amalia Salgado López

y Carolina Escobar Neira

DOI: doi.org/10.24850/b-imta-perspectivas-2020-04

estratégico para garantizar el cumplimiento de los derechos humanos asociados con el agua y su relevancia para alcanzar las metas previstas en la Agenda 2030.

1. https://parlatino.org

2. https://parlatino.org/pdf/documentos/tratado-institucionalizacion-parlatino.pdf

3. https://parlatino.org/leyes-modelo-aprobadas-por-el-parlatino

4. http://www3.diputados.gob.mx/camara/001_diputados/012_comisioneslxii/01_ordinarias/002_agua_p otable_y_saneamiento/13_marco_juridico/01_constitucion_politica_de_los_estados_unidos_mexicano s

5. En ese entonces, los que hoy en día se reconocen como dos derechos humanos independientes seguían considerándose como uno solo.

6. CLOCSAS, Confederación Latinoamericana de Organizaciones Comunitarias de Servicios de Agua y Saneamiento. Antecedentes, evolución y potencialidades. CLOCSAS-AECID. Panamá. 2017. p. 12. Consultaı en: https://drive.google.com/file/d/1ToSU-58KkW3PxGiXnmrTkbiJp-MaHgyo/view

7. https://www.undp.org/content/undp/es/home/sustainable-development-goals/goal-6-clean-waterand-sanitation.html

8. 16.7 Garantizar la adopción en todos los niveles de decisiones inclusivas, participativas y representativas que respondan a las necesidades. Consultar en: https://www.un.org/sustainabledevelopment/es/peacejustice/

9. La asociatividad como estrategia en la gestión comunitaria del agua en Latinoamérica. CLOCSAS. S/N . 2012. Consultar en: https://drive.google.com/file/d/1QBjDzfq5eaLMErEkPErOnG080C8C6VK3/view

10. http://parlamentarioscontraelhambre.org/frentes/nacionales/mexico/ 